\title{
الإطار النظري والتحليلي للتضخم في الكويت
}

عذبي سلمان عبد العزيز مالك الصباح

طالب دكتوره بمعهد البحوث والدرسات الأفريقية - جامعة أسوان لكبران

$$
\text { تحمث عبد الوهاب (بو نحول }
$$

أستاذ الإقتصاد الزراعى - كلية الزراعة - جامعة أسيوط

$$
\text { حرب احمد البرديسي }
$$

أستاذ الإقتصاد الزراعى المساعد - كلية الزراعة - جامعة أسيوط 


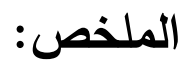

تهدف دراسة الاطار النطري والتحليلي للتضخم في دولة الكويت، وقد توصلت الدراسة إلي أنه لازال معدل التضخم السنوي في الكويت الأعلى مقارنة بالدول الخليجية بالرغم من الدعم الذي تقدمه حكومة الكويت ممثلة بوزارة التجارة لبعض من المواد الغذائية الأساسية على شكل حصص تموينية لكل مواطن، أو بدعم مباشر تقدمه الحكومة للطحين وغاز الطبخ والأعلاف الحيوانية والماء والكهرباء والبنزين والديزل. الكلمات الإفتتاحية الإطار النظرى - التضخم · الكويت

\section{Abstract}

The aim of the study of the theoretical and analytical framework for inflation in the State of Kuwait, The study found that the annual inflation rate in Kuwait is still higher compared to the Gulf countries, despite the support provided by the Kuwaiti government, represented by the Ministry of Trade, for some basic foodstuffs in the form of rations for each citizen, Or with direct support from the government, for flour, cooking gas, animal feed, water, electricity, gasoline and diesel.

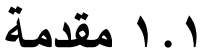

يُعد التضخم من المواضيع الاقتصادية التي تنال أهمية بالغة وخاصة في دراسات المشاكل الاقتصادية المعاصرة ، إذ أصبح الارتفاع في المستوى العام

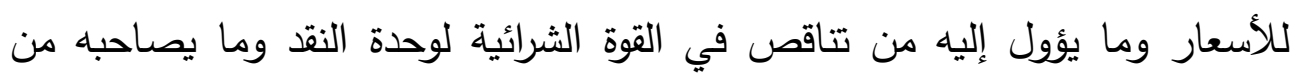

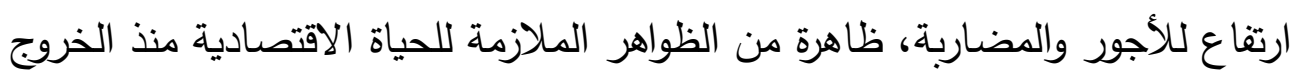
من قاعدة الذهب في بداية السبعينات من القرن الماضي، بحيث لم تفلت أية دولة في العالم من الوقوع في مشاكل التضخم. ولقد شهدت الدول الراسمالية موجات كثيرة من التضخم وصل احيانا إلي معدلات عالية جدا جعلت التضخم يوصف بأنه تضخم جامح، وتتعدد اسباب التضخم 
في الدول المتقدمة منها، الارتفاع الكبير في نفقات الانتاج وكذلك منها ما يتعلق بجانب الطلب، كما تعاني الدول النامية من ارتفاع معدلات التضخم للاسباب نفسها، كما فيالدول المتقدمة ولأسباب اخري تتعلق بالاختلالات الهيكلية والاختناقات من جانب الانتاج والعرض التي تعاني منها هذه الدول. كما يؤدي التضخم إلي اثاراً اقتصادية واجتماعية مهمة علي غالبية الناس الناس وعلي الاقتصاد القومي، لذلك تحاول الدول الحد من التضخم باستخدام السياسات

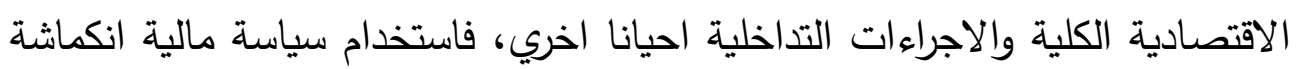
من خلال ارتفاع معدلات الضرائب وتخفيض الانفاق الحكومي يتوقع أن يؤدي إلي تقليل التضخم، كما أن هناك ما يؤيد السياسة النقدية في الحدم من التضخم بإعتبار أن التضخم ظاهرة نقدية ومن ثم ارتباع سياسة نقدية انكماشية كما في حالة تقليل

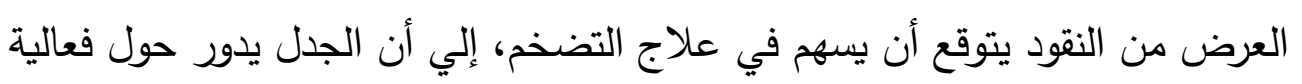

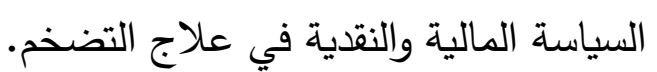
تجدرة الاشارة إلي أن هناك العديد من الدراسات السابقة التي حاولت حسم هذا الجدل حول فاعلية السياسة المالية والنقدية في علاج التضخم إلا أن لم تحسم هذا الجدل، ومن هذه الدراسات دراسة أحمد ححمد صالح جلال (T . . ب)، بعوان "دور السياسة النقدية والمالية في مكافحة التضخم في البلدان انامية: دراسة حالة الجمهورية

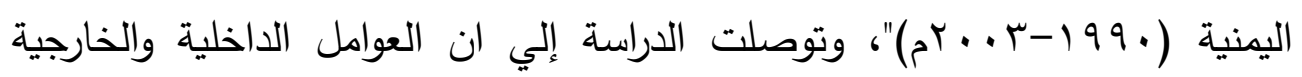
والاختلالات الهيكيلية في بنيان الاقتصاد القومي القومي اليمني، ساهمت في تتامي الضغوط التضخمية في اليمن، كما أدي إلي ارتفاع معدل التضخم في أعلي خلال

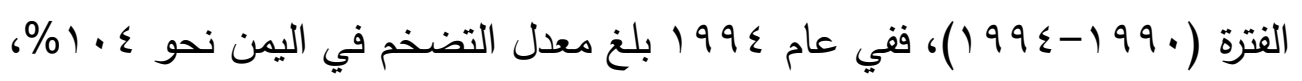
مما صاحبه تدهور شديد في مستوي معيشة شريحة كبيرة في المجتمع اليمني، كما توصلت الدراسة علي الرغم من نجاح السياسة النقدية والمالية في تقليل الضغوط لتئي التضخمية الناتجة عن عوامل محلية كالاستهلاك النائي والانفاق الحكومي المرتفع، تونه إلا أن السياسة المالية والنقدية لم تتجح بعد علاج التضخم المستورد الناتج عن ارتفاع لاعليه

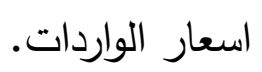


دراسة ليلي علي القشاط (10 (Y)، حاولت الدراسة قياس أثر السياسة النقدية

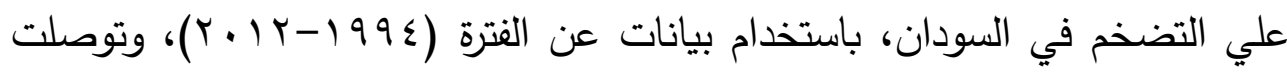
الدراسة إلي أن هنالك ارتباط معنوي وطردي بين العرض من النقود والاحتياطي النقدي

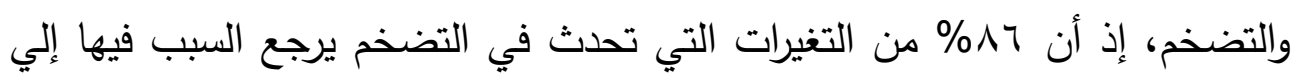

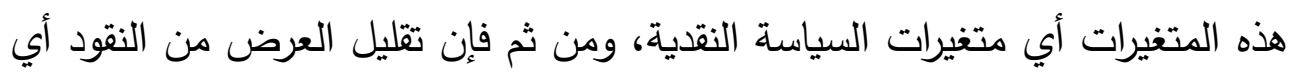
استخدام سياسة نقدية انكماشية يسهم في الحد من التضخم أي فاعلية السياسة النقدية في علاج التضخم بالنسبة لحالة السودان. لكن معالجة التضخم أو علاجه تتطلب معرفة الاسباب التي أدت اليه، لذا الدراسة لتناول ظاهرة الضخم في الاقتصاد الكويت، وفي سبيل تحقيق الهدف يقترح

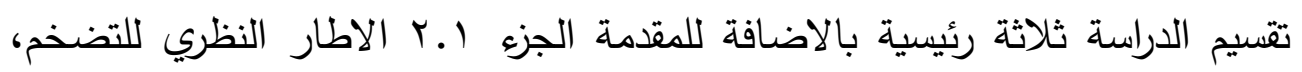
الجزء ا.ب الاطار التحليلي للتضخم في الكويت، الجزء ا.ــ الخلاصة.

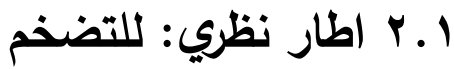

حيث يشتمل هذا الجزء علي تعريف التضخم وأنواع التضخم وأسباب التضخم والاثار الاقتصادية والاجتماعية للتضخم.

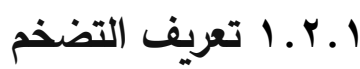

يشير المعنوي الللغوي للتضخم الي الزيادة عن الحجم الطبيعي، اما المعني الاصطلاحي يشير الي الزيادة المستمرة والمتراكمة في المستوي العام للاسعار خلا لـدي فترة زمنية معينة عادة تكون هذه الفترة (سنة)، ولايشترط ان ترتفع جميع الاسعار ربما ترتفع او تتخفض بعض اسعار السلع ولكن العبرة بارتفاع المستوي العام للاسعار ،

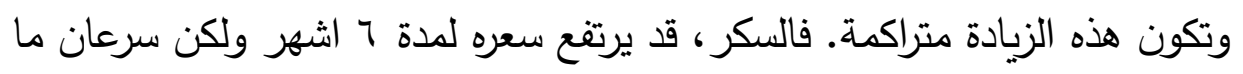

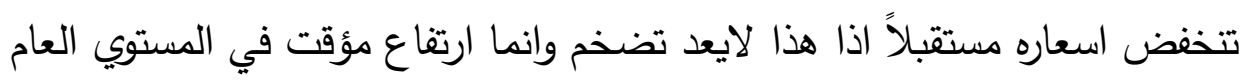

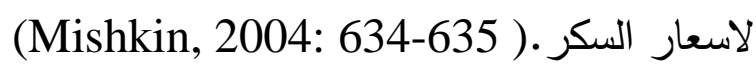


ويتم قياس التضخم عن طريق تتبع التغيرات في اسعار مختلف السلع والخدمات، وهناك العديد من مختلف الارقام القياسية للأسعار، ولكن أكثر شيوعا في قياس التضخم الرقم القياسي لأسعار المستهلكين (CIP)، والرقم القياسي لأسعار المنتج (PPP)، والرقم القياسي والذي يعتبر أكثر شمولاً وهو مكمش الناتج المحلي الاجمالي الحقيقي. الرقم القياسي لأسعار المستهلكين، يقيس التغير في المستوي العام لاسعار السلع والخدمات التي يقوم القطاع العائلي بشرائها في الحضر ـ مثال، عندما يكون الرقم

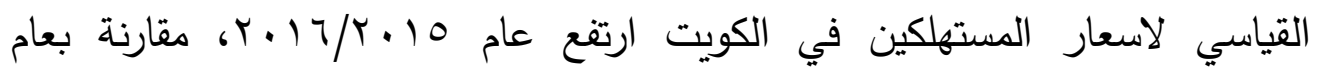

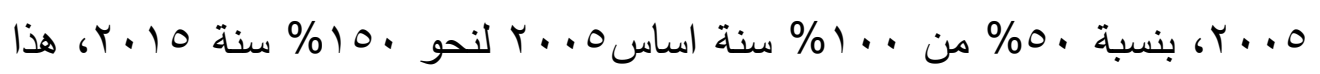
يعني ان القطاع العائلي في الحضر في الاقتصاد الكويتي انفاقه علي بعض السلع والخدمات المستخدمة لقياس الرقم القياسي لاسعار المستهلكين ارتفع بنسبة .0\%

(Oner, 2010: 44)

الرقم القياسي لاسعار المنتج PPP يقيس التغير لاسعار السلع عند المراحل المختلفة للانتاج وبالتالي فهو يحتوي علي الرقم القياسي للسلع النهائية والمواد الوسيطة والمواد الخام، والسلع النهائية: هي سلع لاتحتاج الي اي عمليات صناعية اخري وبالتالي فهي معدة لاستخدام النهائي سواء من قبل القطاع العائلي، او قطاع الاعمال، اما السلع الصناعية: هي سلع مرت بعمليات صناعية ومع ذلك فهي تمر بعدليات

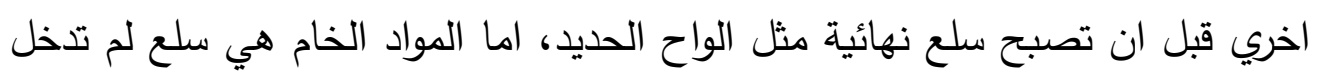
السوق لاول مرة وبالتالي لم تمر باي عمليات صناعية، وبالتالي لابد ان تصنع قبل ان تصبح سلع نهائية كالبترول الخام، والبلاستيك التي يصنع منها البلاستيك. الرقم القياسي لمكمش الناتج المحلي الاجمالي GDP Deplator هو مصطلح اقتصادي يطلق علي النسبة بين الناتج المحلي النقدي، والناتج المحلي الحقيقي، يعتبر الرقم القياسي لمكمش الناتج المحلي الاجمالي افضل هذه المؤشرات لانه بياخذ في اعتباره جميع السلع والخدمات النهائية علي عكس الرقم القياسي لاسعارالمستهلكين الذي يتضمن اسعار مجموعة معينة من السلع والخدمات النهائية. 


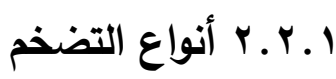

يفرق الاقتصاديين بين انواع مختلفة من التضخم طبقاً لعدة معايير منها، درجة

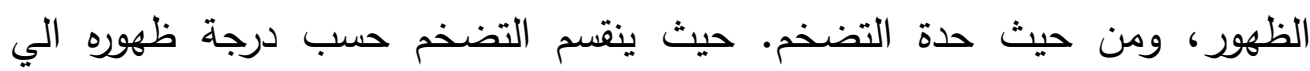

التضخم المفتوح والتضخم المكبوت، أما التضخم المفتوح Open inflation هو زيادة ظاهرة في المستوي العام للأسعار أي أنه ليس هناك تدخل من الحكومة لكبت ارتفاع

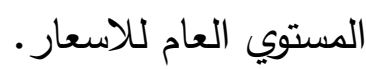

التضخم المكبوت Supressed inflation في هذا النوع من التضخم يكون معدل التضخم اقل مما يجب ان يكون عليه، بسبب تدخل الحكومة لوضع حدود عليا

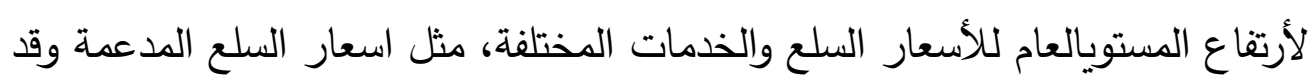

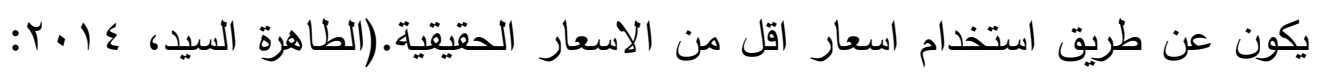
(Y^V

كما ينقسم التضخم من حيث حدته الي التضخم الزاحف، والتضخم العادي، والراكض، والجامح. ويري الاقتصادي Kent في حالة ارتفاع المستوي العام للأسعار

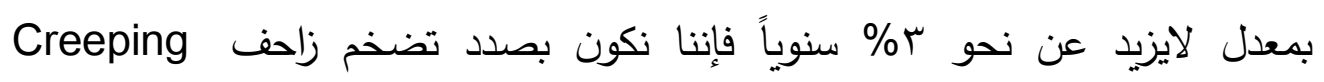

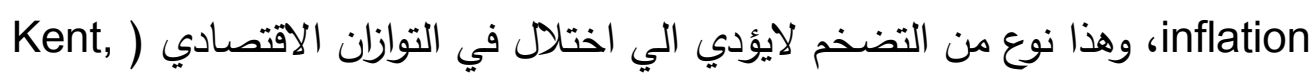

.$(1961: 412$

أما التضخم العادي "الماشي" Walking inflation يحدث عندما يسجل

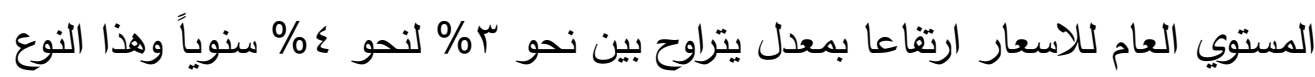
من التضخم يحمل اشارة انذار لإمكانية حدوث التضخم التراكمي أو التضخم الجامح. ويكون الاقتصاد في حالة تضخم راكضRunning Inflation عندما يرتفع المستوي العام للأسعار بنحو · م \% سنويا. بالنسبة للتضخم الجامح Galloping inflation في ظل هذا النوع من التضخم يرتفع المستوي العام للأسعار كل لحظة ولايوجد أي حد للذروة التي يمكن أن في فئ

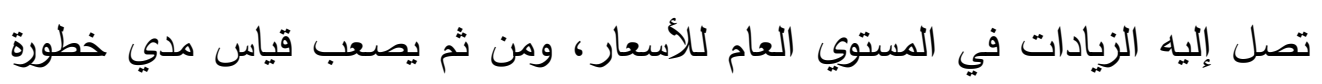
التضخم ذا التضخم الجامح، ويعاني الاقتصاد من تضخم جامح عندما يشهد المستوي 


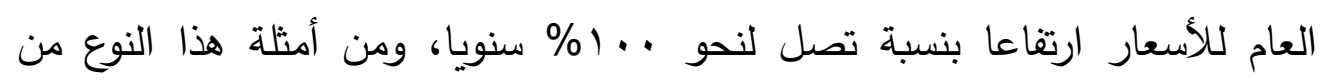

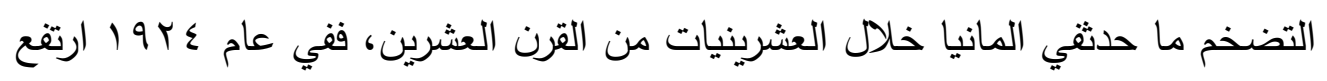

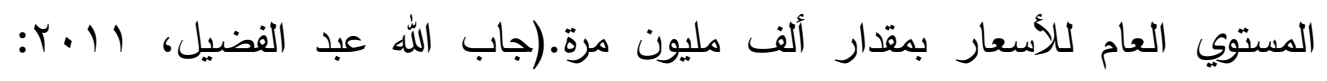

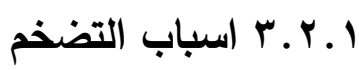

ينقسم التضخم حسب اسبابه أو مصادره الي ثلاثة انواع رئيسية هي: تضخم الطلب، تضخم النفقة، والتضخم الهيكلي، وفيما يلي توضيح لكل واحد منهما.

أ. تضخم الطلب

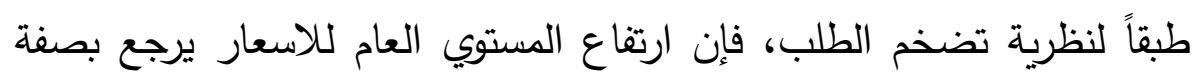

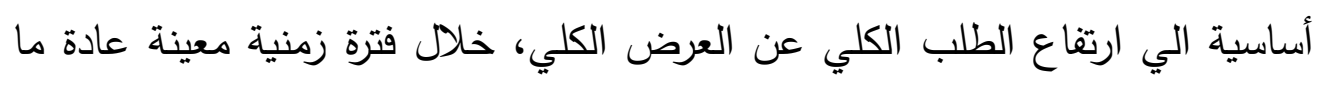

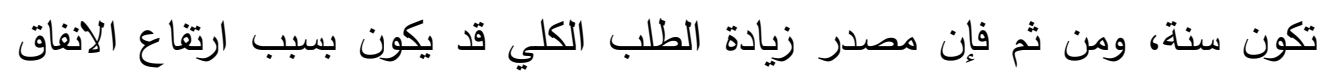

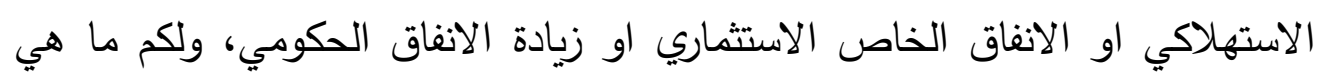

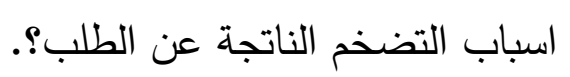
وتؤكد للنظرية الكلاسيكية التي تفترض التوظف الكابه الكامل وثبات متوسط سرعة

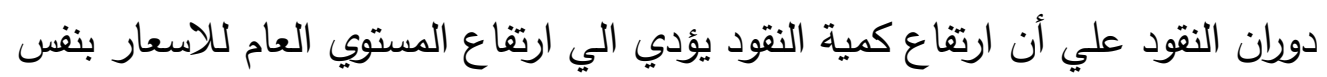

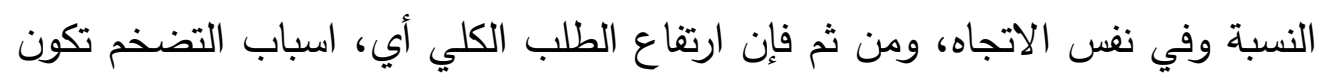

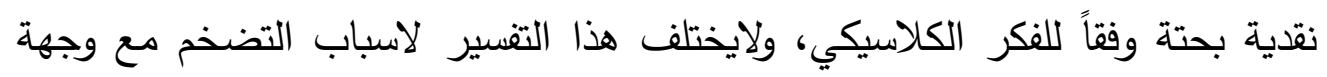

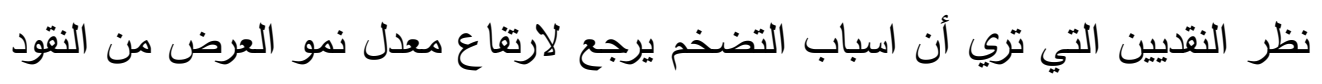

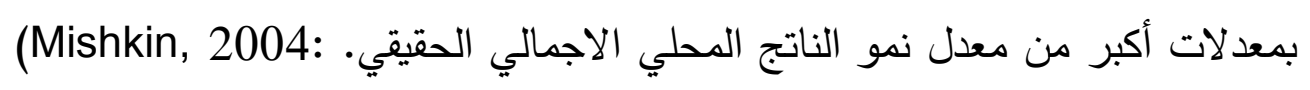

كما يري كينز أن اسباب التضخم ترجع الي الفجوة التضخمية والتي تنثأ نتيجة

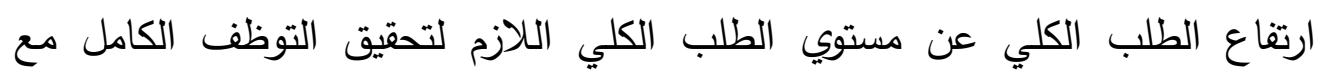
افتراض ثبات العرض من النقود. 
وبصفة عامة فإن هناك العديد من العوامل التي تؤدي الي ارتفاع الطلب النقدي منها، ارتفاع الانفاق الحكومي عن الايرادات العامة دون زيادة في الانتاج، وزيادة حجم الاستثمارات في قطاع الاعمال عن الطاقة الادخارية للاقتصاد، بالاضافة الي ارتفاع الميل الحدي للاستهلاك، اضافة الي وجود عوامل غير نقدية تؤدياليارتفاع الطلب الكلي ومنها ارتفاع معدل النمو السكاني.(جاب الله عبد الفضيل، 11 إ.ب: $\cdot(r v v-r v T$

\section{ب. تضخم النفقة}

حيث أن التضخم يبدأ نتيجة الزيادة في نفقات الاتتاج، وخاصة الاجور فوفقاً

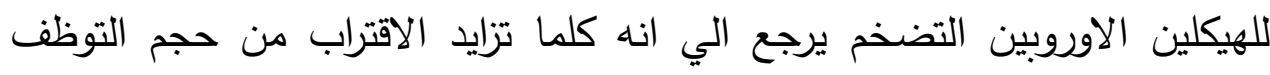

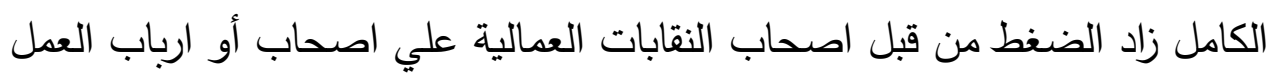
لرفع الاجور ، وسيستجيب اصحاب العمل نظرا لندرة عنصر العمل كلما اقتربنا من

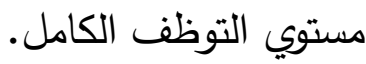
ويُعد من اسباب تضخم النفقة ارتفاع اسعار الطاقة وزيادة اسعار المواد الاولية مما يؤدي الي ارتفاع تكاليف الانتاج وارتفاع معدل التضخم، بالاضافة الي ارتفاع هامش الربح ففي حالة ارتفاع تكاليف الانتاج سوف تقوم المنشآت الاحتكارية بتقليل الكمية المعروضة لرفع المستوي العام للاسعار والحصول علي هامش ربح اعلي، ويعرف التضخم في هذه الحالة بتضخم الربح Profit Push inflation. تجدر الاشارة إلي أن تضخم النفقة لايؤدي الي ارتفاع المستوي العام للاسعار فقط وانما ايضا اليانخفاض الكمية المعروضة من السلع والخدمات، وقد يترتب علي استمر انخفاض الكمية المعروض او العرض الكلي في مراحل تالية ارتفاع معدل البطالة وتحول الاقتصاد من حالة ركود الي مرحلة الكساد، لذا يتطلب مواجهة تضخم النفقة محاربة الاحتكار وتشجيع المنافسة.

\section{ج. التضخم الهيكلي}

يري أنصار نظرية التضخم الهيكلي أن التضخم في البلدان النامية يرجع الي حالة التطور التي تثهدها البلدان النامية في ظل وجود موارد محدودة نسبياً وهوما 
يترتب عليه التوسع في العرض من النقود ومن ثم ارتفاع معدلات التضخم، بالاضافة الي وجود عدة اختتاقات تعاني منها قطاعات الاقتصاد في البلدان النامية ومن هذه الاختاقات قصور البنية التحتية، قصور متحصلات النقد الاجنبي، اختاقات قطاع الزراعة، فجوة الموارد المحلية. بالنسبة لقصور البنية التحتية حيث تعاني البلدان النامية من ضعف البنية التحتية وقصور مصادر الطاقة والاتصالات والطرق وكلها عوامل تعوق النمو الاقتصادي ومن ثم ارتفاع المستوي العام للتضخم، اما عن قصور المتحصلات من النقد الاجنبي ففي ظل عدم مرونة الطلب علي الوردات من الخارج بالنسبة للبلدان

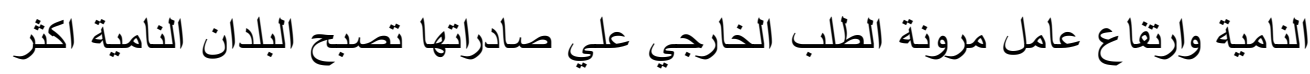
عرضة للعجز في موازين مدفوعاتها خاصة الغير بترولية ومن الحاجة الي موارد من النقد الاجنبي لتمويل العجز في موازين مدفوعاتها.

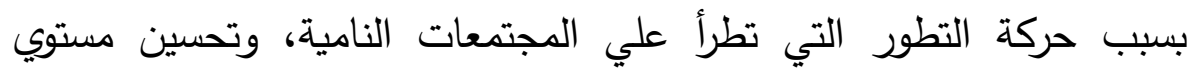
معيشتهم، بالاضافة الي ارتفاع معدل نمو سكانها، فإن طلبهم علي السلع الغذائية يرتفع مع عدم مرونة قطاع الزراعة او استجابته بنسبة اقل من معدل نمو سكانها وبالتالي ارتفاع معدلات التضخم، بالاضافة الي استخدام تكنولوجيا زراعية غير متطورة لا تلاعد علي زيادة الانتاج. اما فجوة الموارد المحلية حيث تعاني الدول النامية من قصور المدخرات

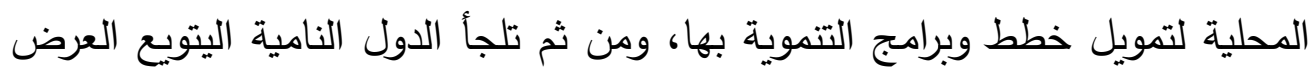
من النقود لتمويل العجز في الادخار بالاضافة الي الجهاز المصرفي الغير المتطور والذي لايسهم بشكل أكثر فاعلية في تجميع المزيد من المدخرات اللازمة لتمويل برامج التنمية.

وهكذا يتضح أن اسباب التضخم في الدول النامية لايمكن اختزالها في العوامل

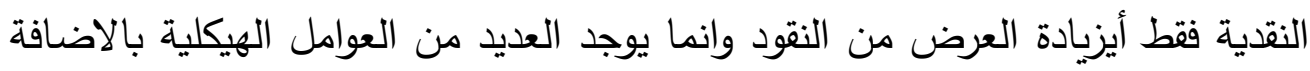
الي تضخم نفقة الانتاج والتي يجب علاجها لمواجهة قصور العرض الكلي عن مواجهة

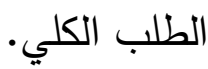




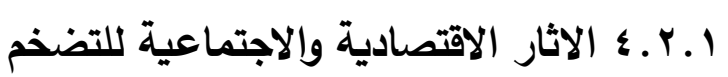

يترتب علي التضخم الكثير من الاثار الاقتصادية والاجتماعية التي تؤثر علي مستوي معيشة المواطن ومستوي رفاهية المواطن وكذلك اقتصاد الدولة وفيما يلي تتاول لهذه

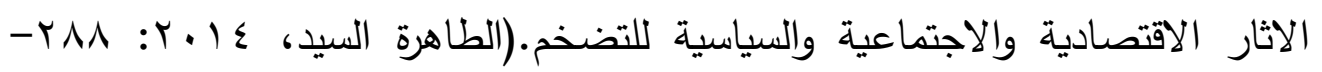

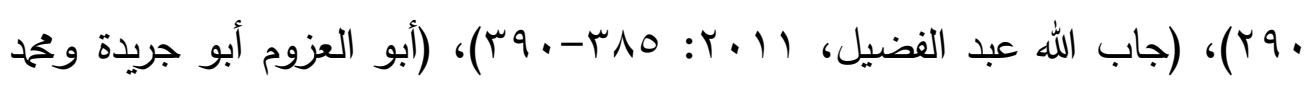

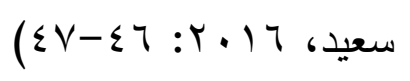

\section{أولاً، الاثار الاقتصادية للتضخم}

أ. أثر التضخم علي قيمة النقود التار

حيث يؤدي ارتفاع المستوي العام للاسعار الي انخفاض القوة الشرائية للنقود

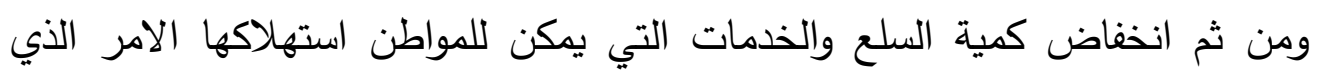
يؤدي الي انخفاض مستوي رفاهية المواطن. ب. أثر التضخم علي الناتج

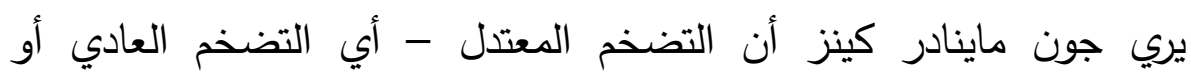
الزاحف- وبافتراض وجود موارد عطلة في الاقتصاد يؤدي التضخم المعتدل الي تحفيز معدل النمو الاقتصادي، فالارتفاع المعتدل للمستوي العام للاسعار يولد توقعات متفائلة

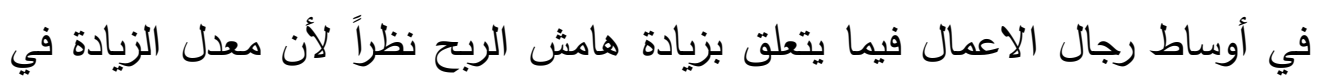

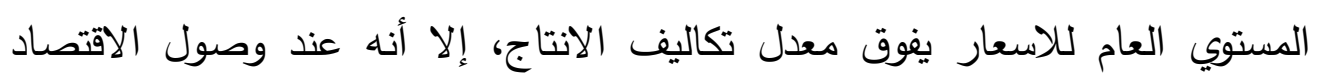

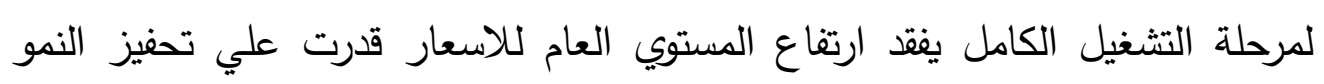
الاقتصادي وزيادة الانتاج والتوظف، حيث يتحول التضخم المعتدل الي تضخم راكض التص

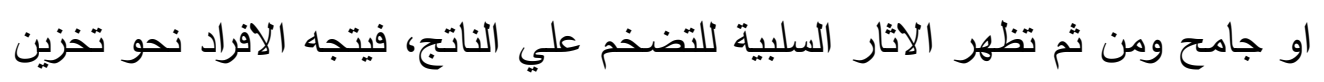
السلع بهدف المزيد من الارباح، وتتدور قيمة المنتجات لان التضخم ينتج ما يسمي بسوق البائعين فارتفاع الطلب يؤدي الي سيطرة البائعين علي السوق والتحكم في

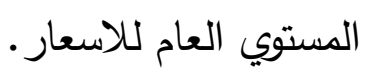


كما يؤدي التضخم الي تدهور القوة الثرائية للنقود ومن ثم اضعاف

$$
\text { ج. احتمالات الادخار في المجتمع وتدور التراكم الراسمالي. }
$$

يؤدي ارتفاع التضخم الي انخفاضالميزة التنافسية للصادرات بسبب ارتفاع

تكاليف الانتاج ومن ثم عدم قدرة الصادرات علي المنافسة العالمية، بالاضافة الي ان سكان الدولة التي منيت بارتفاع المستوي العام للاسعار يجدون دافعا قويا في الشراء

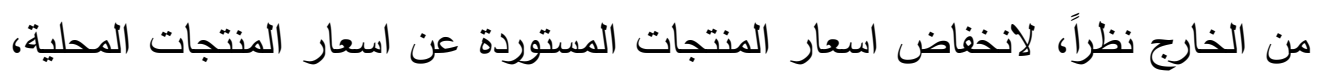
بالاضافة الي التضخم يؤدي الي تدهور قيمة العملة الوطنية وروب رؤوس الاموال

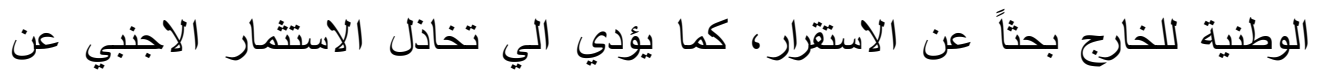

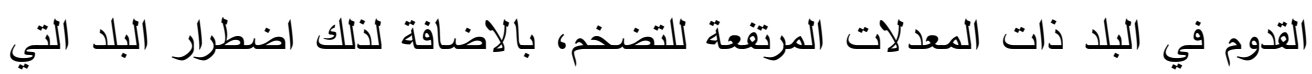
تعاني من عجز مزمن في ميزان مدفوعاتها بسبب التضخم اليسحب احتياطياتها الدولية من الذهب لسداد اثمان وارداتها.

د. آثار التضخم علي توزيع الاخل

بالنسبة لأصحاب الدخول الثابتة، وتشمل هذه الطبقة الاجتماعية صغار

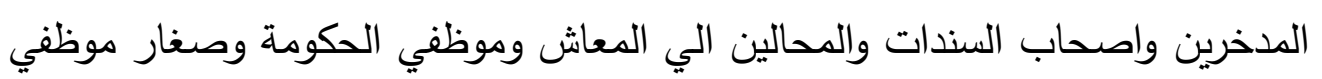

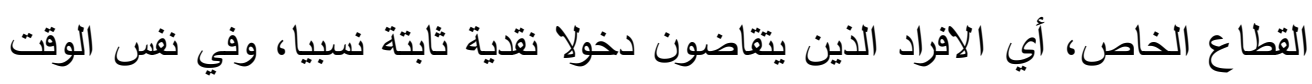
يواجهون بارتفاع المستوي العام للاسعار والخدمات الامر الذي يؤدي الي انخفاض كبير في دخلهم الحقيقي، وقد يقال أن العمال يستطيعون عن طريق نقاباتهم الحصول

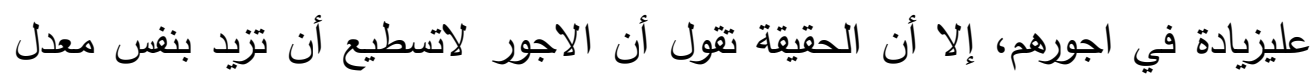

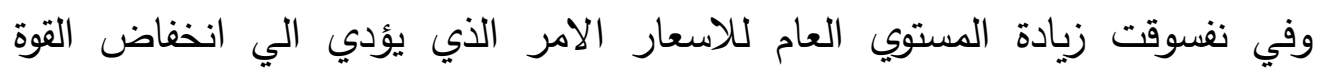
الثرائية لهؤلاء الافراد.

اما اصحاب الدخول المتغيرة وهم اصحاب الفئات الاجتماعية التيتستطيع الحصول علي مزيد من الدخل عند ارتفاع المستوي العام للاسعار، كالفئات التي 
تحصل علي ارباح كالمضاربين والتجار واصحاب المصانع واصحاب الاسهم خاصة في الشركات الكبيرة، حيث يرس هؤلاء ان معدل الارتفاع في المستوي العام للاسعار يفوق معدل ارتفاع تكاليف الانتاج ومن ثم يحصلون علي هامش ربح اعلي.

ثانياً، الاثار الاجتماعية والسياسية للتضخم حيث يترتب علي التضخم العديد من الاثار الاجتماعية والسياسية منها، خلق موجات من السخط الجماعي والتذمر نحو المواطنين والانفلات السياسي مما يؤدي الي لي زيادة الاضطربات وارتفاع حدة المواجهة بين العمال ورجال الاعمال والحكومة العاجزة عن معالجة التضخم، بالاضافة الي تدهور اخلاقيات بعض رجال الاعمال والاتجار

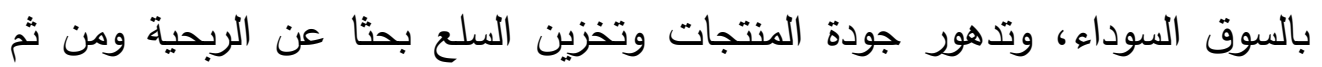
ظهور ازمات مفتعلة تؤدي الي نقص العرض. ا.ب الاطار التحليلي: للتضخم في الكويت تشير الاحصائيات الصادرة في تقرير افاق الاقتصاد العربي الي انخفاض

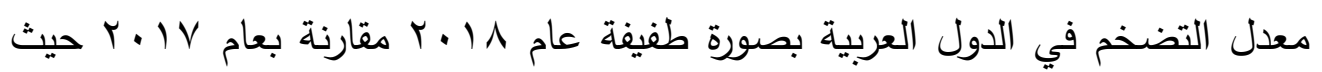

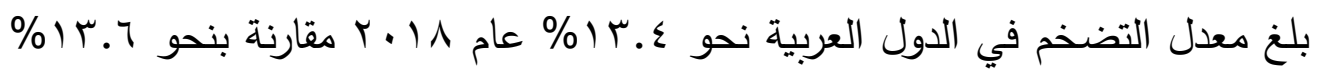
عام V P Y Y، ويمكن تبرير اسباب انخفاض التضخم في الدول العربية بسبب الاجراءات التقسفية التي تم تطبيقها داخل البلدان العربية للحد من التضخم، حيث تم تطبيق سياسات مالية ونقدية انكماشية في اطار برامج الاصلاح الاقتصادي والتي ترتب عليا تطبيق ضريبة القيمة المضافة والخفض التدريجي لمستويات الدعم السلعي، ورفع الرسوم الجمركية علي بعض السلع. (تقرير افاق الاقتصاد العربي، أبريل 9 ( ب ؟: r)

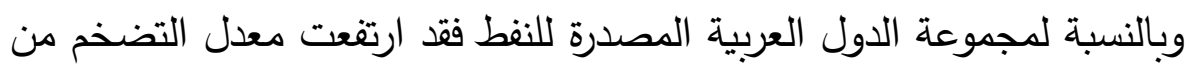

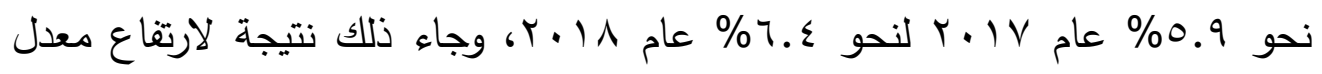

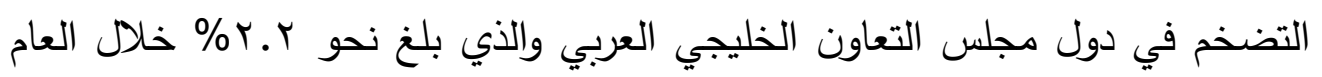

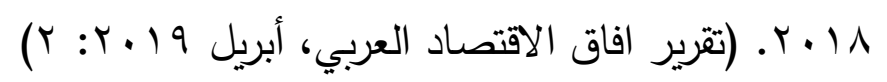


وتشير الاحصائيات الي وجود اتجاه تصاعدي للتضخم في الاقتصاد الكويتي

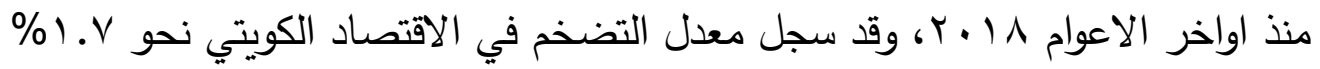

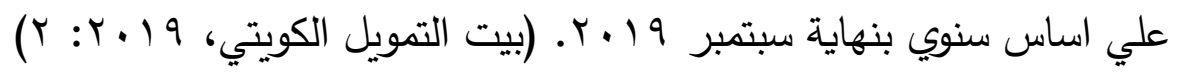
ويهدف الجزء r.r الي تحليل ظاهرة التضخم في الاقتصاد الكويتي لمعرفة مدي تطور ظاهرة التضخم في الاقتصاد الكويتي ومدي تحقيق الاقتصاد الكويتي

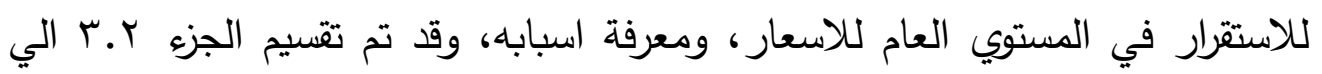

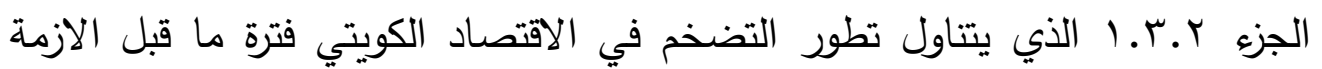

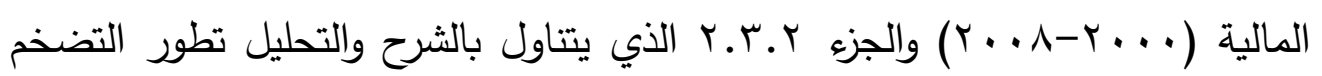

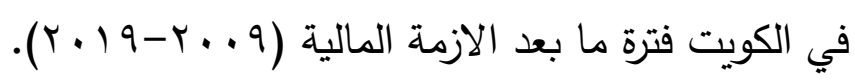

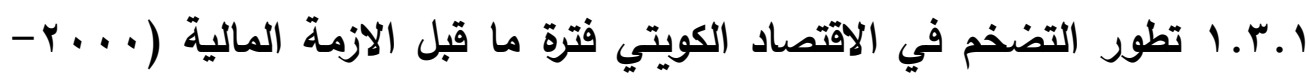

$$
(r \cdot \Lambda
$$

يمكن معرفة الاتجاه العام للتضخم في الكويت خلال الحقبة الاولي من القرن الواحد وعشرين وهي فترة ما قبل الازمة المالية بالاعتماد علي بيانات البنك الدولي كما

هو موضتح في الشكل (1)

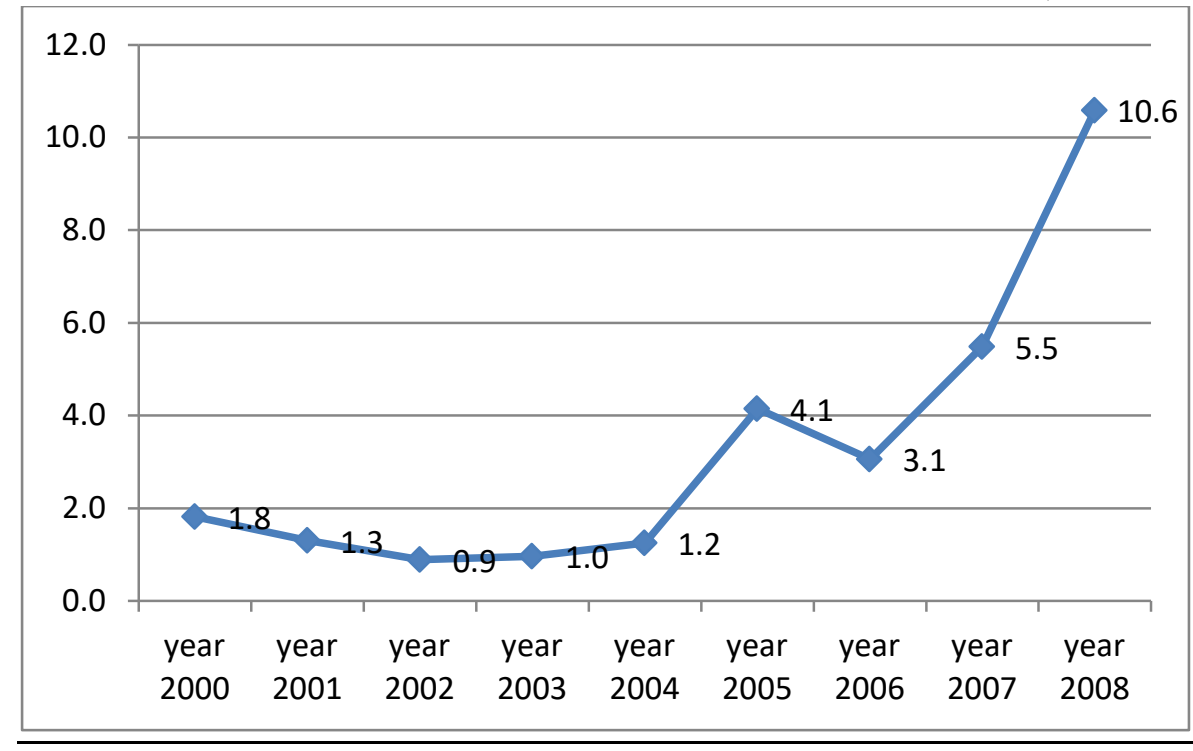

شكل (1) يوضح تطور معدل التضخم في الكويت خلال الفترة ( . . . - - . . . م) المصدر: بيانات البنك الدولي 
يتضح من الثكل (1) أن معدل التضخم في الاقتصاد الكويتي مقاساً بالتغير

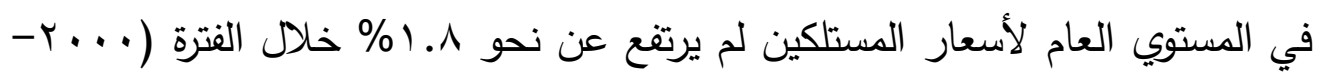

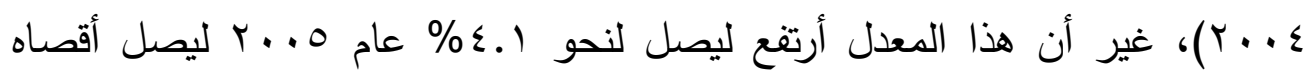

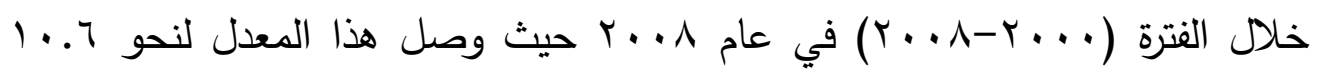
وهي بداية الازمة المالية العالمية، ورغم ذلك فإن متوسط معدل التضخم في الكويت

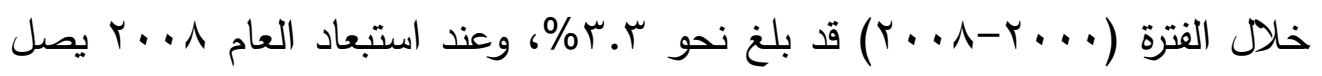

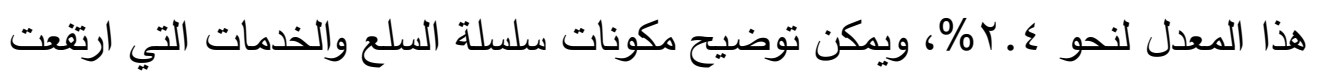

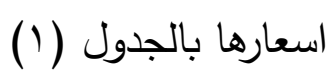
جدول (1) يوضتح الرقم القياسي لأسعار المستهلكين في الكويت خلال الفترة $(r \cdot \Lambda-r \cdot \neg)$

\begin{tabular}{|c|c|c|c|c|c|c|}
\hline \multirow{2}{*}{\multicolumn{3}{|c|}{ ألتَغيز (\%) }} & \multirow{2}{*}{\multicolumn{3}{|c|}{ المرقم القياسي لأسعار المستهلي }} & \\
\hline & & & & & & \\
\hline$r \cdot \Lambda$ & $r \ldots v$ & $r+T^{\prime}$ & $r \cdot \Lambda$ & $r . v$ & $r \cdot T$ & \\
\hline $9, r$ & $\checkmark, r$ & $r, \wedge$ & $1 \leq 1$, & $1+9,1$ & $1 \times 1,2$ & المواد المذأثية \\
\hline $1 \leq, 9$ & $\cdot, r$ & 0,1 & $|r|, v$ & $11 \leq, 7$ & $11 \leq, \varepsilon$ & المشرويات ورالتبغ \\
\hline$\bullet, \wedge$ & $0, v$ & 7,0 & Irr, & r & 119,0 & الكساء وملبوسات القدم \\
\hline 17,1 & $1, r$ & $r$ & Irv, & $1.9,8$ & $1 \cdot \wedge, \cdot$ & خذمات السكن \\
\hline I & $r, \tau$ & $\varepsilon, r$ & 117,9 & $1 \cdot r, \Lambda$ & $1 \cdot 1, r$ & سلع وخدمات منزلية \\
\hline$\{, 1$ & $9, \cdot$ & $\cdot, 0$ & $11 \pm$ & $1.9,0$ & $1 \cdots, 0$ & النقل و المو اصلات \\
\hline ir, & $r, r$ & $v, \varepsilon$ & $1 \leq 1,1$ & $1+7, \cdot$ & I rq, & الخذمات التعليمية و الصحية \\
\hline $0, \wedge$ &, \pm 0 & $\checkmark, v$ & $1+0,$. & $11 \wedge, 1$ & $11 r$, & سلع وخدمات أخرى \\
\hline $1 \cdot, 1$ & $\varepsilon, r$ & $r, \wedge$ & $1 r v, 1$ & 110,4 & $11 \cdot, \wedge$ & الزرقم القياسب العام \\
\hline
\end{tabular}

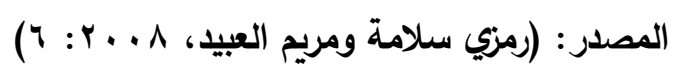
يتضح من الجدول (1) أن خدمات السكن يليها المواد الغذائية بما فيها المشروبات، فالخدمات التعليمية والصحية من أبرز مكونات سلسلة السلع والخدمات

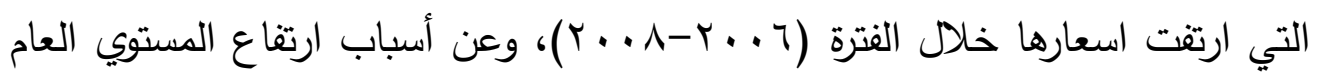

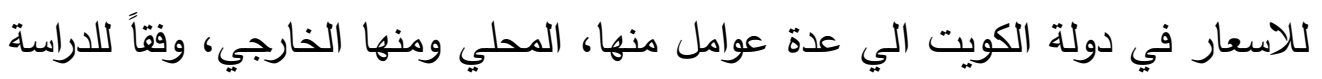

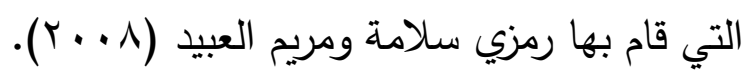


وبالنسبة للعوامل المحلية لارتفاع التضخم في الكويت، تتمثل في: ضعف أدوات السياسة المالية اللازمة لمكافحة التضخم في الكويت، فلازال دور الموازنة العامة مقتصراً علي اعادة توزيع الموارد النفطية دون أن تصبح الموازنة العامة أداة تخطيط اقتصادي ومالي تساعد علي كبح جماح التضخم. المضاربة علي اسعار الاراضي والعقارات، وجدير بالذكر أن الحكومة الكويتية

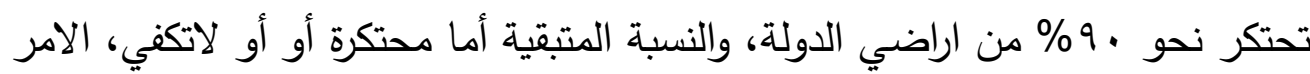
الذي يؤدي الي ارتفاع تكاليف الانتاج حيث ينعكس ذلك علي اسعار السلع والخدمات، والايجار والاجور، وزيادة الانفاق الحكومي من خلال دعم الاسكان أو دعم المواد الاساسية. بالاضافة الي ارتفاع اسعار المواد الغذائية نتيجة تطبيق التعريفة الجمركية

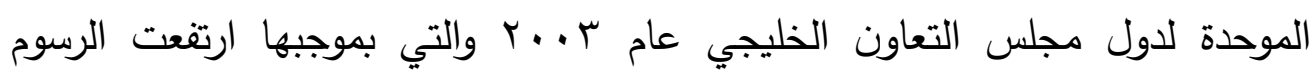
الجمركية علي المواد الغذائية المستوردة من نحو صفر \% لنحو ٪\% ٪.(رمزي سلامة

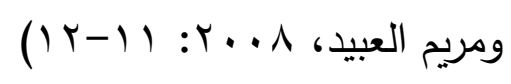

التوسع في التسهيلات الأتمانية، حيث ارتفعت التسهيلات الأيتمانية الشخصية

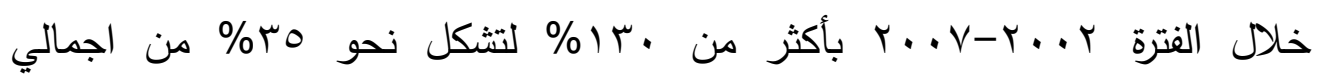
التسهيلات الائتمانية حتي نهاية سبتمبر V. ...، بالاضاة الي انتشار ظاهرة البيع بالتقسيط وهو الامر الذي أدي الي ارتفاع الطلب الكلي بشكل كبير، بالاضافة الي لهاب ارتفاع سعر "التقسيط" عن السعر "النقدي، وكلها عوامل تؤدي الي ارتفاع المستوي

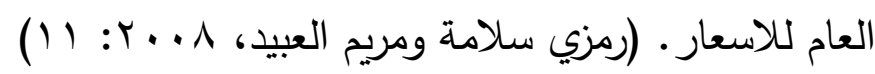
وجود بعض البؤر الاحتكارية، وذلك في سياسة الانفتاح التجاري لدولة الكويت

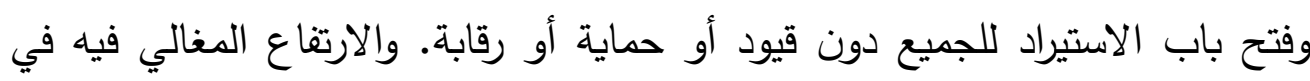
الانفاق الترفيهي وهو أعلي من الانتاج الحقيقي، وهذا له انعكاسات مباشرة علي سلوك

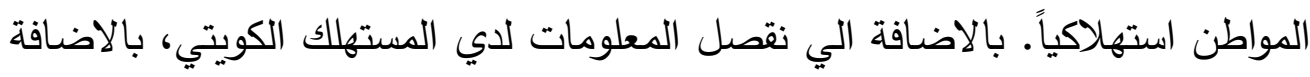
الي عدم مرونة المستهلك الكويتي في التحول الي السلع البديلة، بالاضافة الي النزعة الاستهلاكية والميول الشرائية وانتشار الاستهلاك الاستفزازي جعلت كل مواطن يطمح 
الي مستوي معيشة يفوق دخله. والزيادات المتتالية في أجور ورواتب المواطنين تستحث التجار علي رفع الاسعار • المعائ. أما العوامل الخارجية، فمنها، التضخم المستورد، لاسيما وأن الاقتصاد الكويتي يعتمد علي أكثر من •9\% من حاجة البلاد من السلع الاستهلاكية والوسيطة والمعمرة،

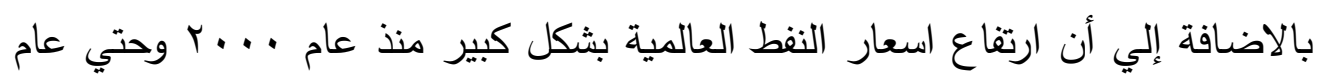

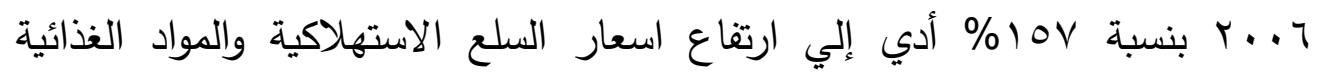

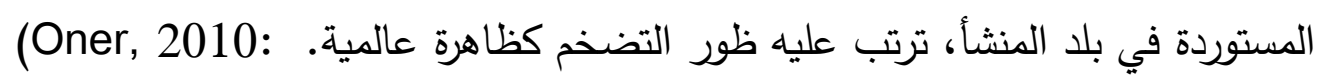

ارتفاع الاسعار العالمية لتكاليف خدمات الثحن البحري والجوي والنقل وخدمات التامين بأنواعه، وانعكاس ذلك علي اسعار السلع والخدمات في الكويت. والكوارث الطبيعة، مثل الفيضانات والجفاف وتأثر المحاصيل بتلك العوامل بالاضافة واتعات الي انتشار انفلونزا الطيور وجنون البقرالامر الذي أدي الي ارتفاع بعض المنتجات الحيوانية والطيور في الاسواق العالمية.

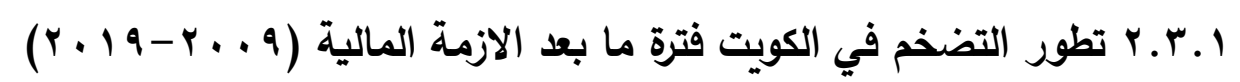
يمكن الاعتماد علي بيانات قاعدة البنك الدولي لمعرفة تطور التضخم في

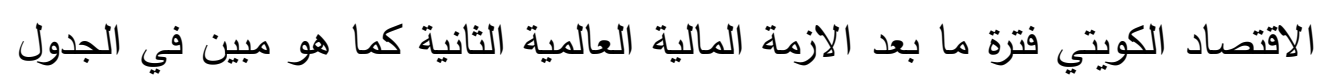

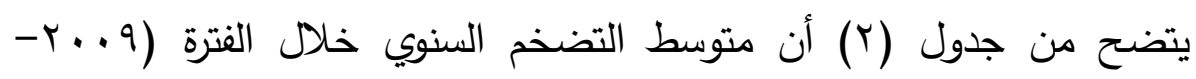

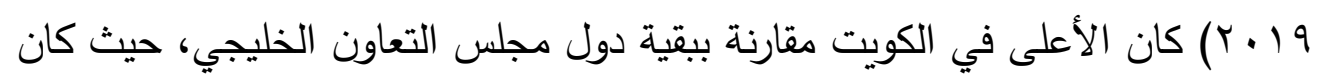
متوسط معدل التضخم السنوي في الكويت نحو 3.3\% لتلك الفترة، وجاءت السعودية في المرتبة الثانية بمتوسط معدل تضخم سنوي بلغ نحو 3\% والبحرين في المرتبة الثالثة بمتوسط معدل تضخم سنوي قدر بنحو ا.ب\%؛ وعمان في المرتبة الرابعة بمتوسط معدل تضخم سنوي قدر بنحو 9. (\%)، والامارات في المرتبة الخامسة بمعدل 
تضخم بلغ نحو ^. (\% وأخيرا جاءت قطر في المرتبة الاخيرة بمتوسط معدل تضخم

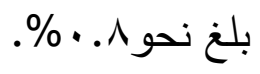

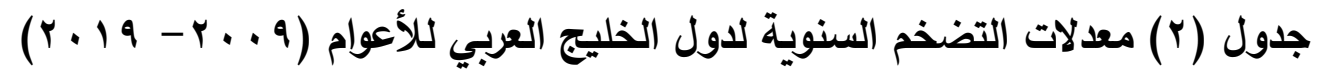

\begin{tabular}{|c|c|c|c|c|c|c|c|}
\hline & الكويت & قطر & عمان & السعودية & البحرين & الامارات & المتوسط \\
\hline year 2009 & 4.6 & -4.9 & 3.5 & 5.1 & 2.8 & 1.6 & 2.1 \\
\hline year 2010 & 4.5 & -2.4 & 3.3 & 5.3 & 2.0 & 0.9 & 2.3 \\
\hline year 2011 & 4.8 & 1.1 & 4.0 & 5.8 & -0.4 & 0.9 & 2.7 \\
\hline year 2012 & 3.3 & 2.3 & 2.9 & 2.9 & 2.8 & 0.7 & 2.5 \\
\hline year 2013 & 2.7 & 3.2 & 1.0 & 3.5 & 3.3 & 1.1 & 2.5 \\
\hline year 2014 & 2.9 & 3.4 & 1.0 & 2.2 & 2.6 & 2.3 & 2.4 \\
\hline year 2015 & 3.3 & 1.6 & 0.1 & 1.2 & 1.8 & 4.1 & 2.0 \\
\hline year 2016 & 3.2 & 2.9 & 1.1 & 2.1 & 2.8 & 1.6 & 2.3 \\
\hline year 2017 & 2.2 & 0.4 & 1.6 & -0.8 & 1.4 & 2.0 & 1.1 \\
\hline year 2018 & 1.1 & 0.3 & 0.9 & 2.5 & 2.1 & 3.1 & 1.7 \\
\hline المتوسط & 3.3 & 0.8 & 1.9 & 3.0 & 2.1 & 1.8 & \\
\hline
\end{tabular}

المصدر قاعدة بيانات البنك الدولي.

وكان التضخم السنوي في الكويت أعلى من متوسط معدل التضخم لدول

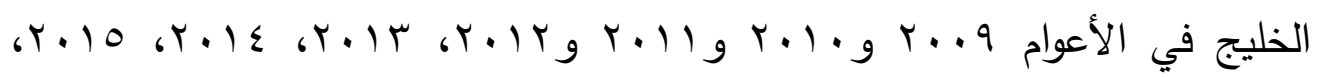

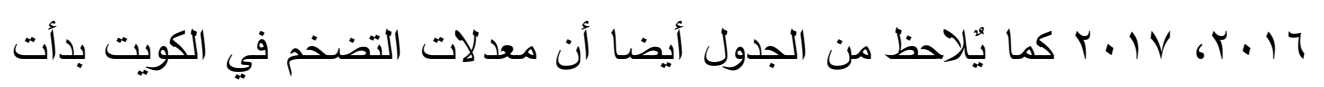

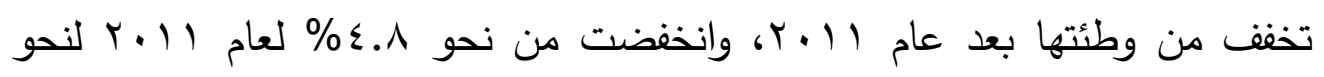

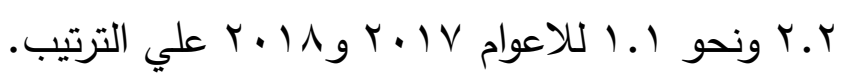

وجدير بالملاحظة أن معدلات التضخم السنوي في الكويت لتلك الفترة هي الأعلى مقارنة بالدول الخليجية بالرغم من الدعم الذي تقدمه حكومة الكويت ممثلة

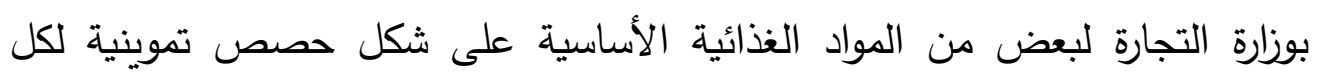
مواطن، أو بدعم مباشر تقدمه الحكومة للطحين وغاز الطبخ والأعلاف الحيوانية والماء والكهرباء والبنزين والديزل، يستفيد منه جميع من يعيش على أرض الكويت.

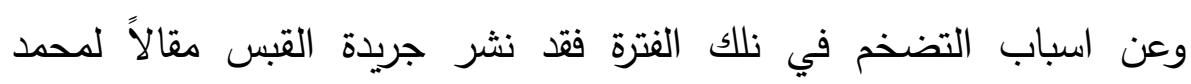

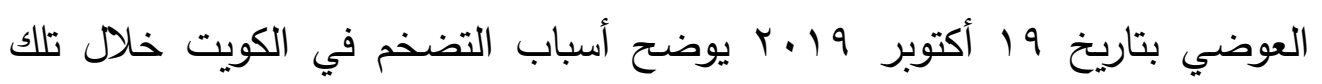
الفترة، حيث يؤكد العوضي علي أن معظم التضخم الحادث في الكويت وكذلك في دول 
مجلس التعاون الخليجي التي تستورد معظم حاجاتها من السلع من الخارج هو تضخم مستورد، فخلال العقد الاول من القرن الواحد وعشرين شهد الاقتصاد العالمي نموا عاليا متسارعا، والذي كان من أهم أسباب الطفرة التي حدثت لأسعار النفط خلال تلك الفترة، والذي أدى بدوره إلى حدوث تضخم عالمي في أسعار المنتوجات تم تصديره على شكل تضخم في أسعار السلع للدول المستوردة. بالاضافة لذلك فقد ساهمت ثورة المعلومات المتمثلة بوسائل التواصل الاجتماعي على الدفع بوتيرة الاستهلاك لكثير من أنواع السلع والخدمات.

والمصدر الثاني للتضخم في الكويت وفقاً للعوضي يتمثل في توفر السيولة لاى كثير من المواطنين بعد زيادة الكوادر المالية لمعظم الجهات التابعة للقطاع الحكومي وكذلك لشركات النفط، فالعرض الكبير للنقود مقابل طلب كبير على سلع محددة سيؤدي بالتالي إلى تضخم إضافي لأسعار تلك السلع والذي سينعكس بشكل مباشر على الرقم القياسي لسعر المستهلك، ويعكس الثكل تطور العرض من النقود

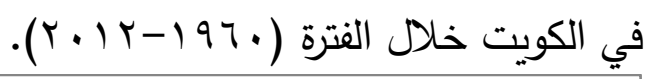
القيم بالمليون دينار كويتي

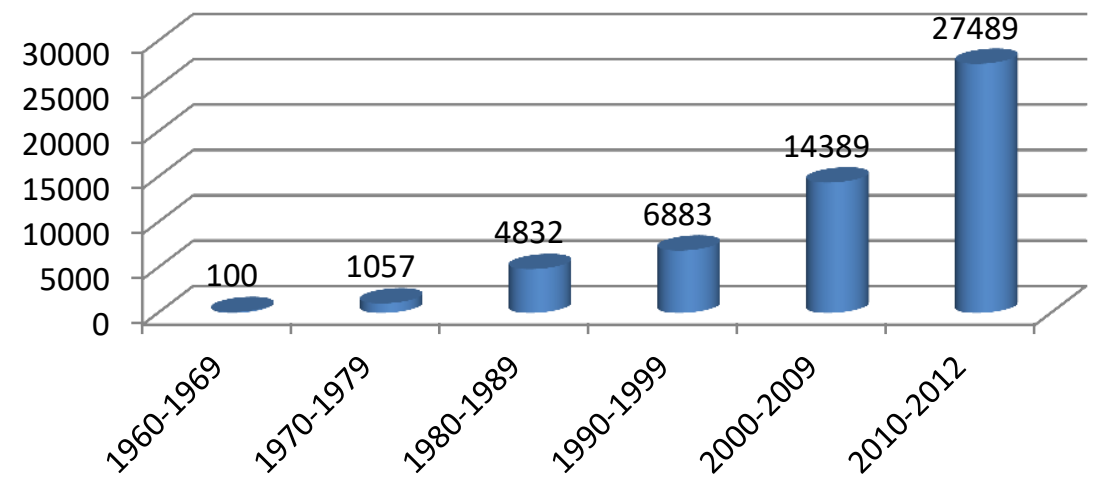

شكل (Y) عرض النقود بمفهومه الواسع M2 في الكويت خلال الفترة ( . 9 ( $(r \cdot 1 r$

المصدر: بنك الكويت المركزي (ع مايو با.بr )، "السياسة النقدية لبنك الكويت المركزي: الإطار العام والتوجيهات 
يتضح من الثكل (Y) قد أن العرض من النقود بمفهوم الواسع في الاقتصادي

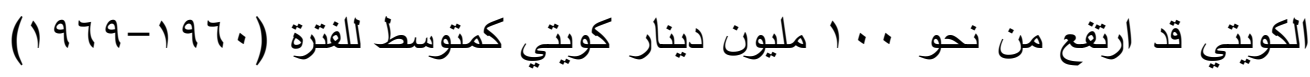

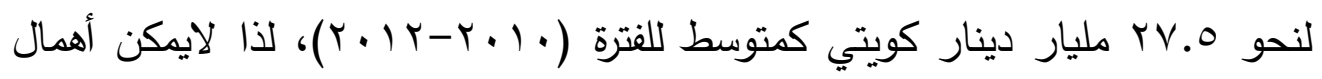
العرض من النقود كأحد العوامل التي أدت الي ارتفاع التضخم في الكويت نسبياً أي التئي بالنسبة لمثيله في دول الخليج المناظرة.

\section{1. ـ الخلاصة}

تهدف دراسة الاطار النطري والتحليلي للتضخم في دولة الكويت، وفي هذا الاطار تم تقسيم الدراسة الي ثلاثة أجزاء رئيسية بالاضافة الي المقدمة الجزء الثاني الاطار النظري للتضخم، الجزء الثالث الاطار التحليلي للتضخم في الكويت، الجزء

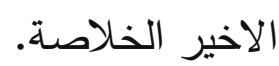

وقد أشتمل الجزء الثاني اطار نظري: للتضخم علي تعريف التضخم وأنواع التضخم وأسباب التضخم والاثار الاقتصادية والاجتماعية للتضخم، حيث يمكن لتهن تعريف التضخم بأنه الزيادة المستمرة والمتراكمة في المستوي العام للأسعار، أما أنواع التضخم حيث يفرق الاقتصاديين بين انواع مختلفة من التضخم طبقاً لعدة

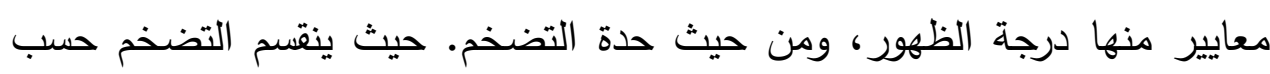
درجة ظهوره الي التضخم المفتوح والتضخم المكبوت، ومن حيث حدة التضخم ينقسم التضخم الي التضخم الزاحف، والتضخم العادي، والراكض، والجامح.

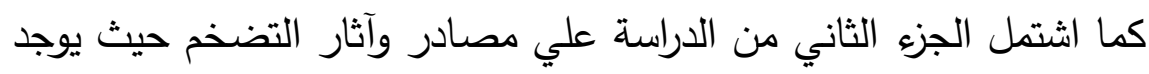
ثلاثة مصادر رئيسية تؤدي للتضخم هي تضخم الطلب، تضخم النفقة، والتضخم الهيكلي. ويترتب علي التضخم الكثير من الاثار الاقتصادية والاجتماعية التي تؤثر علي مستوي معيشة المواطن ومستوي رفاهية المواطن وكذلك اقتصاد الدولة وفيما يلي تتاول لهذه الاثار الاقتصادية والاجتماعية والسياسية للتضخم، حيث يؤثر التضخم علي قيمة النقود والناتج وميزان المدفوعات وإعادة توزيع الدخل بالاضافة الي الاثار الاجتماعية والسياسية للتضخم. 
أما الجزء الثالث فقد اشتمل علي اطار تحليلي للتضخم في الكويت، وقد تم تقسيم الجزء ץ.ب الي الجزء ץ.r.l الذي يتتاول تطور التضخم في الاقتصاد

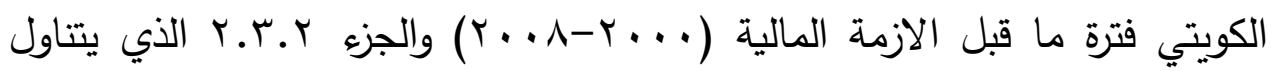

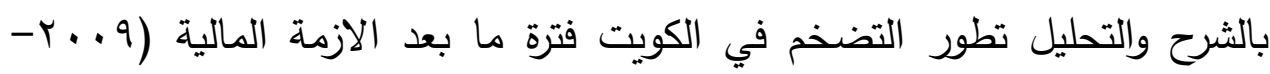
19 (r). حيث لازال معدل التضخم السنوي في الكويت الأعلى مقارنة بالدول

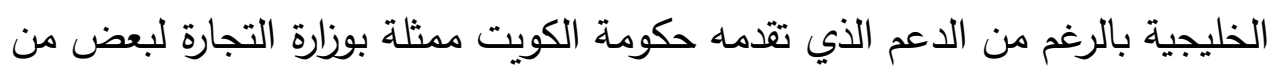
المواد الغذائية الأساسية على شكل حصص تموينية لكل مواطن، أو بدعم مباشر تقدمه الحكومة للطحين وغاز الطبخ والأعلاف الحيوانية والماء والكهرباء والبنزين والديزل، وتضمن الجزء الاخير الخلاصة. 


\section{الــــراجع}

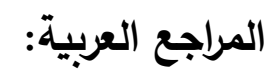

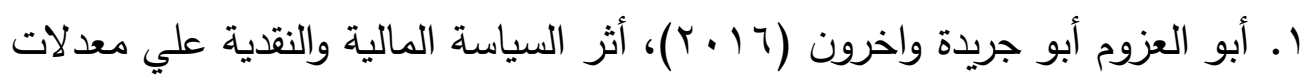

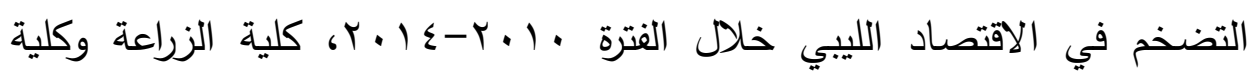
الاقتصاد والمحاسبة، مركز اللغات، جامعة سبها، ليبيا، ص و وب-rT.

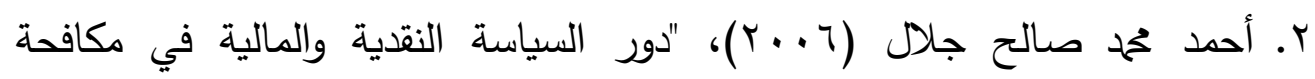

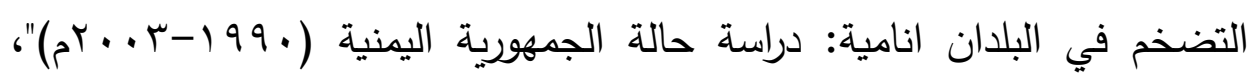
رسالة ماجستير، كلية العلوم الاقتصادية وعلوم التسيير ، ج. الجزائر .

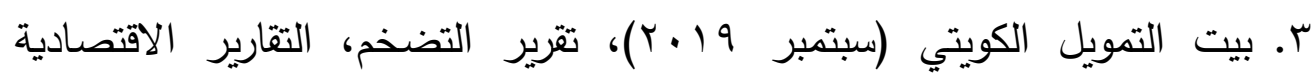
والاستراتيجية والعلاقات المؤسسية. ع. جاب الله عبد الفضيل(1) (1)، التحليل الاقتصادي الكلي، قسم الاقتصاد، جامعة حلوان.

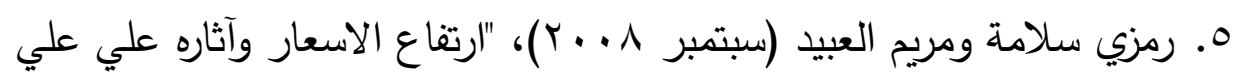

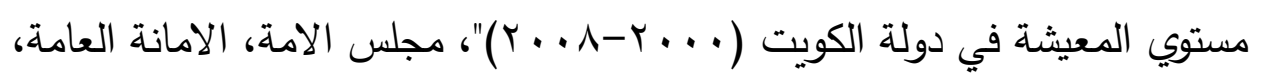
قطاع البحوث والمعلومات، إدارة البحوث والدراسات، قسم الدراسات الاجتماعية.

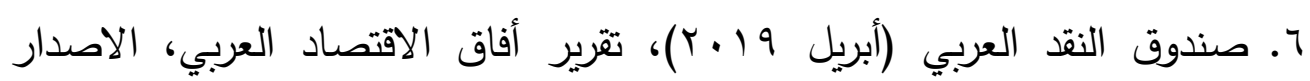

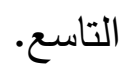
V. الطاهرة السيد (ع ( ب)، الاقتصاد الكلي منظور تحليلي، جهاز نشر وتويع الكتاب

$$
\text { الجامعي، جامعة حلوان. }
$$

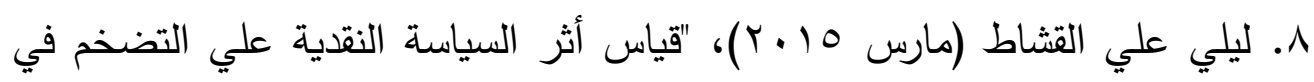

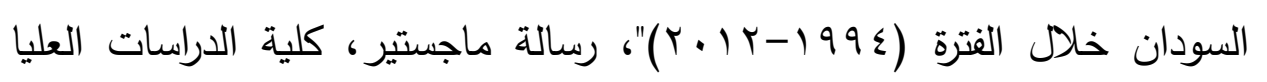
والبحث العلمي، جامعة شندي. 


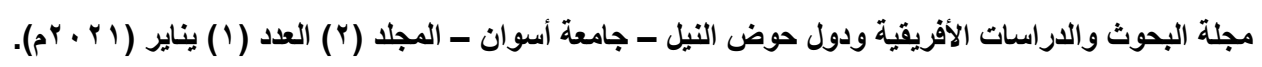

$$
\begin{aligned}
& \text { 9. ححم العوضي (9 أكتوبر } 7 \text { ( ـ ץ)، "التضخم في الكوبت الأعلي خليجياً"، جريدة } \\
& \text { القبس الكويتية. }
\end{aligned}
$$

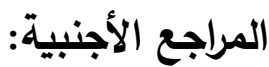

10. Kent, R.P., (1961), "Money and Banking", New York, Holt Rinehart and Winston.

11. Mishkin, S.F., (2004), "The economics of money, banking, and financial markets", Without publisher, 7th, USA.

12. Oner, C., (March 2010),"what is inflation?", Finance \& Development, IMF. 